\title{
PERFIL DOS USUÁRIOS E SUA PERCEPÇÃO DOS ELEMENTOS DE COMPOSIÇÃO PAISAGÍSTICA DAS PRAÇAS DE CURITIBA-PR
}

\author{
USERS' PROFILE AND THEIR PERCEPTION OF LANDSCAPE COMPOSITION \\ ELEMENTS OF CURITIBA-PR'S SQUARES
}

Jennifer Viezzer ${ }^{1}$, Daniela Biondi ${ }^{2}$, Antonio Carlos Batista ${ }^{3}$, Desiree Brandt ${ }^{4}$

\begin{abstract}
RESUMO
O objetivo deste estudo foi conhecer o perfil dos usuários das praças de Curitiba-PR e investigar sua percepção dos elementos de composição paisagística, relacionando-a com as linhas projetuais paisagísticas brasileiras. Para isso, foram aplicados 320 questionários em 32 praças (10 questionários/praça). A maioria dos usuários das praças é habitante de Curitiba (75,3\%), tem entre 11 e 20 anos $(24,7 \%)$, possui ensino superior completo (28,4\%), e usa as praças para descanso e lazer $(57,8 \%)$ todos os dias $(56,9 \%)$. A minoria conhecia o nome da praça onde estava $(33,1 \%)$, porém a maior parte sabia a época em que a praça foi criada $(56,0 \%)$. As árvores foram o elemento mais citado, independente da linha paisagística, e a atenuação da poluição e o conforto térmico foram os benefícios mais reconhecidos pelos entrevistados. Conhecer o perfil e a percepção dos usuários permite compreender a importância das praças para a população urbana.
\end{abstract}

Palavras-chave: Paisagismo; Áreas verdes; Arborização urbana.

\begin{abstract}
The aim of this study was to know the profile of Curitiba-PR's Squares users and investigate their perception of landscape composition elements, relating it to the Brazilian landscape styles. For this, we applied 320 questionnaires in 32 squares (10 questionnaires/square). Most users of the squares is resident of Curitiba $(75.3 \%)$, are between 11 and 20 years old $(24.7 \%)$, has completed higher education (28.4\%), and uses the squares for rest and recreation (57.8\%) every day $(56.9 \%)$. The minority knew the name of the square (33.1\%), but most knew the time when the square was created $(56.0 \%)$. The trees were the most frequently cited element, independent of landscape style, and the pollution mitigation and climatic comfort were the benefits most often recognized by respondents. Knowing the profile and the perception of users allows understanding the importance of squares for the urban population.
\end{abstract}

Keywords: Landscaping, Green areas, Urban forestry.

Recebido em 02.05.2016 e aceito em 14.07.2016

1 Engenheira Florestal, MSc., Analista Ambiental do Ministério do Meio Ambiente (MMA), Brasília/DF. E-mail: jeviezzer@yahoo.com.br

2 Engenheira Florestal, Dra., Professora Titular do Departamento de Ciências Florestais, UFPR, Bolsista de Produtividade em Pesquisa - CNPq, Curitiba/PR. E-mail: dbiondi@ufpr.br

3 Engenheiro Florestal, Dr., Professor Titular do Departamento de Ciências Florestais, UFPR, Bolsista de Produtividade em Pesquisa - CNPq, Curitiba/PR. E-mail: batistaufpr@ufpr.br

4 Graduanda em Engenharia Florestal, UFPR, Curitiba/PR. E-mail: dbrand@ufpr.br 


\section{INTRODUÇÃO}

Símbolo maior da sociabilidade da paisagem urbana, as praças evocam lembranças na memória e na imaginação dos habitantes das cidades. São áreas que desempenham funções essenciais às cidades e seus cidadãos, por meio de seus aspectos ecológicos, sociais, históricos, culturais e de identidade. A praça é uma das tipologias de áreas verdes mais reconhecidas em todo o mundo e a mais presente e identificada nas cidades brasileiras (BIONDI; LIMA NETO, 2012), gerando diversos benefícios às populações urbanas (VOLPE-FILIK; SILVA; LIMA, 2007; ROBBA; MACEDO, 2010).

No Brasil, as áreas verdes obedeceram à três linhas projetuais paisagísticas brasileiras: eclética, moderna, e contemporânea (ROBBA; MACEDO, 2010). Cada linha possui características distintas (tabela 1) que podem revelar as mudanças nos costumes e no passar do tempo de uma sociedade.

Tabela 1. Linhas projetuais paisagísticas brasileiras

Table 1. Brazilian landscape styles

\begin{tabular}{|c|c|c|}
\hline LINHAS PROJETUAIS PAISAGÍSTICAS & ANOS & $\begin{array}{c}\text { PRINCIPAIS } \\
\text { CARACTERÍSTICAS }\end{array}$ \\
\hline \multirow{4}{*}{ Eclética } & \multirow{4}{*}{$1783-1933$} & Espécies exóticas \\
\hline & & Áreas impermeáveis \\
\hline & & Geometria/Simetria \\
\hline & & Estilo clássico \\
\hline \multirow{4}{*}{ Moderna } & \multirow{4}{*}{$1934-1989$} & Espécies nativas \\
\hline & & Áreas de utilidade pública \\
\hline & & Desenhos orgânicos \\
\hline & & Sentimento nacionalista \\
\hline \multirow{4}{*}{ Contemporânea } & \multirow{4}{*}{$1990-$ atual } & Recuperação de áreas \\
\hline & & Liberdade \\
\hline & & Irreverência \\
\hline & & Inovação \\
\hline
\end{tabular}

Fonte: baseado em Silva et al., 2007; Carneiro, Silva e Mafra, 2007; Robba e Macedo, 2010; Oliveira et al., 2013.

O objetivo deste estudo foi conhecer o perfil dos usuários das praças de Curitiba-PR e investigar sua percepção sobre os elementos de composição paisagística das praças, relacionando-a com as linhas projetuais paisagísticas brasileiras. O estudo visa entender a relação entre a população urbana e as praças, seus benefícios e suas histórias, uma vez que Curitiba possui forte ligação com o discurso ambiental e políticas historicamente voltadas à valorização de áreas verdes, dentre elas conservar as praças da cidade como áreas de saneamento e como locais ajardinados e arborizados (BAHLS, 2006). 


\section{MATERIAL E MÉTODOS}

A cidade de Curitiba, capital do Estado do Paraná, coordenadas $25^{\circ} 25^{\prime} 41^{\prime \prime} \mathrm{S}$ e $25^{\circ} 25^{\prime}$ 41 " W, possui uma área de 435,036 km², está localizada a 934,6 metros de altitude, e possui relevo levemente ondulado, com colinas suavemente arredondadas, dando-Ihe uma fisionomia relativamente regular (IPPUC, 2016).

Curitiba possui 1.751.907 habitantes (IBGE, 2016) e um índice de áreas verdes de 64,5 m²/hab., com 454 praças dentre 1.066 áreas verdes (SMMA, 2008).

Para este estudo buscou-se classificar as praças de Curitiba nas três linhas paisagísticas brasileiras - eclética, moderna e contemporânea - de acordo com as suas datas de criação. Para isso, foi necessário que as praças tivessem nomes próprios (muitas praças da cidade não possuem identificação), pois, sem eles, não foi possível encontrar suas datas de criação. Então, dois critérios foram pré-determinados para se definir a população a ser estudada nesta pesquisa: possuir nome próprio e data de criação.

Das 454 praças, 157 ou 34,6\% atenderam os critérios estabelecidos. Buscaram-se os decretos de criação e as datas de inauguração das praças por meio da Secretaria Municipal do Meio Ambiente de Curitiba e junto aos arquivos da Casa da Memória de Curitiba.

Das 157 praças que compõem a população deste estudo, 32 praças foram sorteadas aleatoriamente para fazerem parte do levantamento ( $20 \%$ da população), apresentadas na tabela 2 com suas respectivas datas de criação.

Tabela 2. Praças amostradas, com respectivos ano de criação e linha paisagística Table 2. Squares sampled, with year of creation and landscape style

\begin{tabular}{clcc}
\hline № & PRAÇAS & $\begin{array}{c}\text { ANO DE } \\
\text { CRIAÇÃO }\end{array}$ & $\begin{array}{c}\text { LINHA PROJETUAL } \\
\text { PAISAGÍsTICA }\end{array}$ \\
\hline 1. & Tiradentes & 1880 & Eclética \\
\hline 2. & Carlos Gomes & 1890 & Eclética \\
\hline 3. & José Borges de Macedo & 1898 & Eclética \\
\hline 4. & Santos Andrade & 1901 & Eclética \\
\hline 5. & Garibaldi & 1946 & Moderna \\
\hline 6. & do Redentor & 1953 & Moderna \\
\hline 7. & da Espanha & 1955 & Moderna \\
\hline 8. & Padre João Bagozzi & 1961 & Moderna \\
\hline 9. & Alfredo Andersen & 1969 & Moderna \\
\hline 10. & Villa Lobos & 1970 & Moderna \\
\hline 11. & Abílio de Abreu & 1974 & Moderna \\
\hline 12. & Itália & 1975 & Moderna \\
\hline 13. & Isaac Milder & 1976 & Moderna \\
\hline 14. & Presidente Eisenhower & 1977 & \\
\hline
\end{tabular}


...continuação

\begin{tabular}{|c|c|c|c|}
\hline 15. & Tobias Bueno Arruda & 1978 & Moderna \\
\hline 16. & Francisco R. A. de Macedo & 1980 & Moderna \\
\hline 17. & Nova República & 1985 & Moderna \\
\hline 18. & Lúcia Bozza Pilatti & 1991 & Contemporânea \\
\hline 19. & Piazza San Marco & 1992 & Contemporânea \\
\hline 20. & Padre Agostinho Legros & 1992 & Contemporânea \\
\hline 21. & do Japão & 1993 & Contemporânea \\
\hline 22. & Vivian Calopreso Braga & 1994 & Contemporânea \\
\hline 23. & Nelson Monteiro & 1994 & Contemporânea \\
\hline 24. & Rio Iguaçu & 1994 & Contemporânea \\
\hline 25. & Padre Dario Zampiero & 1995 & Contemporânea \\
\hline 26. & Professora Rosa Kolody & 1997 & Contemporânea \\
\hline 27. & da Colonização Menonita & 2000 & Contemporânea \\
\hline 28. & Irene Pereira e Silva & 2000 & Contemporânea \\
\hline 29. & Loris Scorsin & 2000 & Contemporânea \\
\hline 30. & Emirados Árabes Unidos & 2001 & Contemporânea \\
\hline 31. & Domingas Bianco Stoco & 2009 & Contemporânea \\
\hline 32. & Professor Doutor Manoel Lourenço Branco & 2012 & Contemporânea \\
\hline
\end{tabular}

Foram aplicados 10 questionários por praça, totalizando 320 questionários. Segundo Alreck e Settle (2004), nas pesquisas tipo survey, como estes questionários, uma amostra composta por 300 respondentes já traz níveis estatísticos satisfatórios de confiança e erro amostral, com confiança de $95 \%$ e erro menor do que 10\% em relação à média real da população, independentemente do tamanho da população. Acima desta quantidade, não há uma diminuição significativa do erro e a pesquisa se torna pouco vantajosa em termos de custo-benefício.

O questionário aplicado aos usuários das praças está apresentado na figura 1. 
PRAÇA:

DATA:

GÊNERO: $\square$ Masculino ESCOLARIDADE: $\square$ Ensino fundamental incompleto $\square$ Feminino

$\square$ Ensino fundamental completo

$\square$ Ensino médio incompleto

IDADE: anos

$\square$ Ensino médio completo

CIDADE DE ORIGEM:

$\square$ Ensino superior incompleto

$\square$ Ensino superior completo

1. VOCÊ SABE O NOME DESTA PRAÇA? $\square$ Sim $\square$ Não

2. QUANDO VOCÊ ACHA QUE ESTA PRAÇA FOI CRIADA?

$\square$ Antes de $1935 \quad \square$ Entre 1935 e $1990 \quad \square$ Depois de 1990

3. QUAIS DESTAS PALAVRAS VOCÊ USARIA PARA DESCREVER ESTA PRAÇA?
Clássica
Nacionalista
Inovadora

4. COMO VOCÊ USA ESTA PRAÇA? $\square$ Descanso e lazer $\square$ Ponto de encontro $\square$ Passagem $\square$ Turismo $\square$ Atividade física $\square$ Contato com a natureza

5. COM QUE FREQUÊNCIA VOCÊ UTILIZA ESTA PRAÇA?

6. O QUE TE CHAMA MAIS ATENÇÃO NESTA PRAÇA?

$\square$ Caminhos $\square$ Chafariz $\square$ ponte $\square$ Gramado $\square$ flores $\square$ Árvores $\square$ Bancos $\square$ Luminárias $\square$ Parquinho $\square$ Monumentos $\square$ Outro:

7. NA SUA OPINIÃO, QUAL É A IMPORTÂNCIA DA VEGETAÇÃO NESTA PRAÇA? Conservação da natureza $\square$ Abrigo p/fauna $\square$ Bem estar/menos stress Amenizar a poluição $\square$ Infiltração água da chuva $\square$ Beleza cênica Melhoria do conforto térmico $\square$ Educação Ambiental $\square$ Outro:

Figura 1. Questionário aplicado nas Praças de Curitiba

Figure 1. Survey applied on Curitiba's Squares 


\section{RESULTADOS E DISCUSSÃO}

O perfil do usuários das praças de Curitiba está apresentado na figura 2.

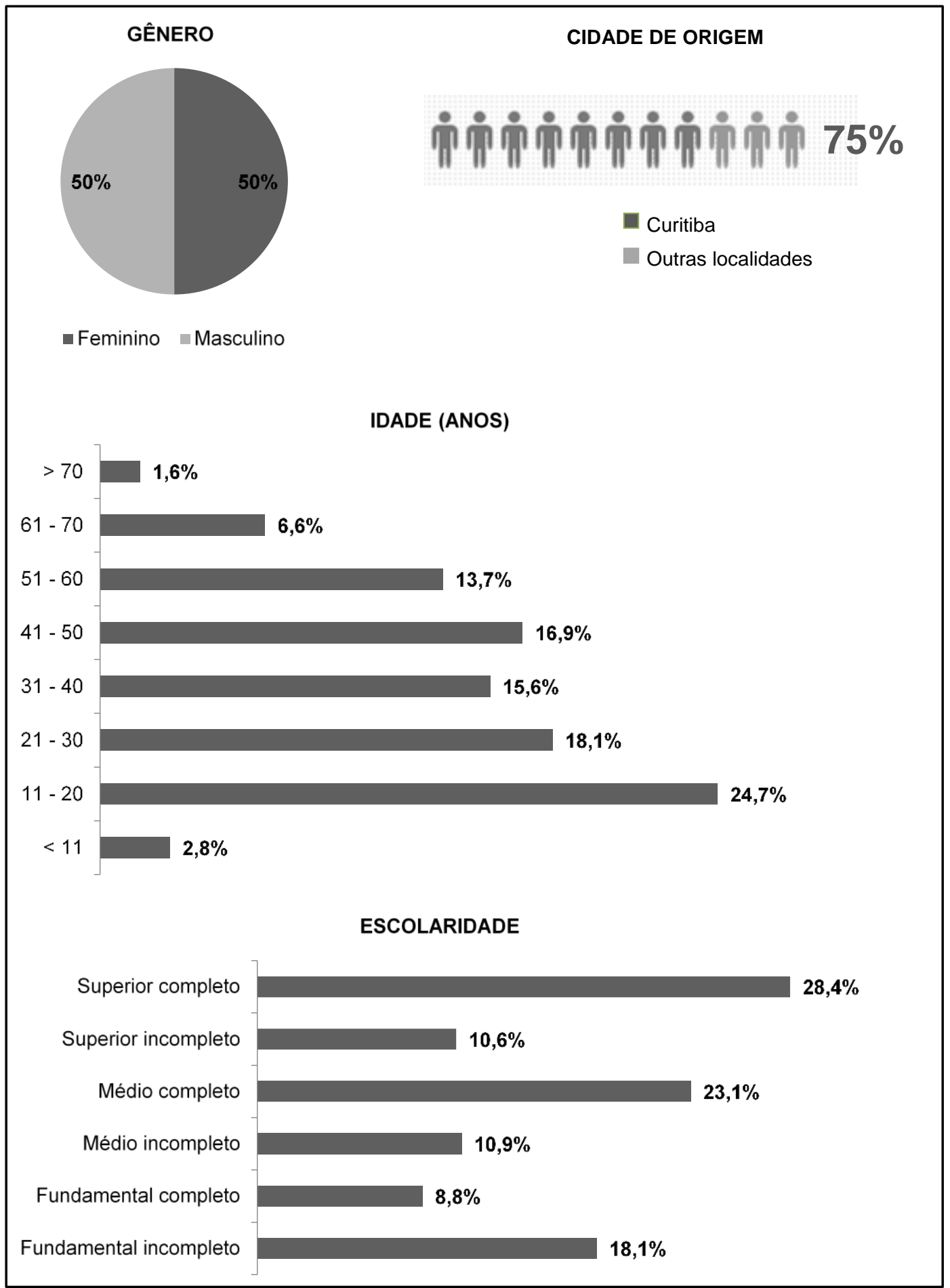

Figura 2. Perfil dos usuários das praças de Curitiba-PR

Figure 2. Profile of Curitiba-PR's square users 
Dos 320 entrevistados, $50 \%$ eram do gênero feminino e $50 \%$ do gênero masculino. Segundo IBGE (2016), a população de Curitiba é composta por 52,3\% de mulheres e 47,7\% de homens, então os usuários das praças representam a distribuição de gêneros da cidade.

A maioria dos entrevistados respondeu ser Curitiba sua cidade de origem, representando 75,3\% dos usuários. Dos demais, 10,6\% eram de outras cidades do Paraná, e $14,1 \%$ eram de outros estados ou países. Em uma pesquisa nos parques de Curitiba, Hildebrand (2001) encontrou $75,4 \%$ de moradores de Curitiba e $24,6 \%$ de turistas, resultado muito próximo ao encontrado nesta, mostrando que os habitantes da cidade são os mais assíduos usuários de ambas as tipologias de áreas verdes.

Quanto à idade, os usuários abordados tinham desde oito até 89 anos de idade. Aproximadamente uma em cada quatro pessoas entrevistadas eram jovens entre 11 e 20 anos $(24,7 \%)$. Em seguida aparecem as classes dos 21 aos 30 anos, dos 41 aos 50 anos, e dos 31 aos 40 anos, com 18,3\%, 16,9\% e 15,6\%, respectivamente. De acordo com IBGE (2016), a faixa etária com maior número de pessoas em Curitiba é entre 21 e 30 anos, com 18,5\% da população, seguida pela faixa entre 31 e 40 anos, com 16,7\%, e então a faixa entre 11 e 20 anos, que representa $15,4 \%$ da população da cidade. Isto demonstra a importância da praça para as crianças e jovens curitibanos com 11 a 20 anos, uma vez que eles são o terceiro grupo de idade com maior número de pessoas, porém é o primeiro grupo em visitação das praças. Hildebrandt (2001) encontrou nos parques a maioria entre 30 a 39 anos, e 20 a 29 anos, com 25,8\% e 25,1\%, respectivamente, havendo então uma diferença entre os principais usuários dos parques e das praças de Curitiba. Silva et al. (2008), ao estudar duas praças de Lavras (MG), também encontrou uma maioria de $27,7 \%$ entre os jovens de 15 e 20 anos.

Em relação à escolaridade, a maioria dos usuários das praças possuía ensino superior completo, representando $28,4 \%$, seguido por $23,1 \%$ com ensino médio completo, $18,1 \%$ com ensino fundamental incompleto, 10,9\% com ensino médio incompleto, 10,6\% com ensino superior incompleto, e finalmente $8,8 \%$ com ensino fundamental completo. Segundo IBGE (2016), a maioria da população de Curitiba possui ensino fundamental incompleto, representando $27,7 \%$, e $17,5 \%$ tem superior completo. Silva et al. (2008) constataram que $21 \%$ dos usuários das praças de Lavras (MG) possuíam ensino superior. Em uma pesquisa sobre uma praça em São Paulo (SP), Brígido e Hirau (2011) também encontraram uma maioria de 45\% dos usuários com ensino superior completo.

Para caracterização do perfil do usuário das praças, também foram realizadas questões quanto ao uso e frequência de visitação das praças, apresentadas na figura 3. 


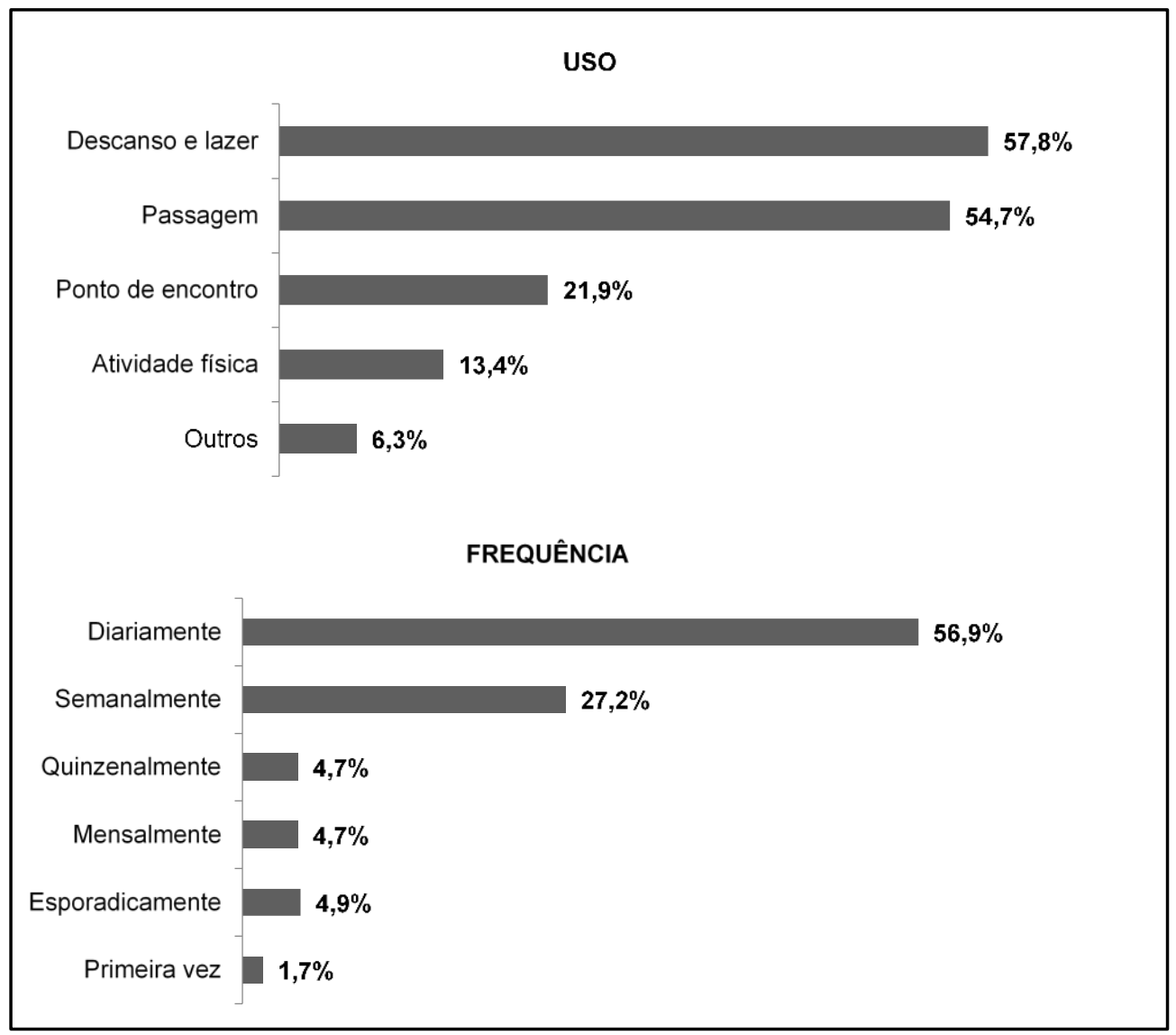

Figura 3. Motivo de uso e frequência de visitação dos usuários das praças de Curitiba-PR Figure 3. Reason and frequency of visitation of Curitiba-PR's square users

A maioria dos entrevistados usa as praças para descanso e lazer $(57,8 \%)$, e também como passagem (54,7\%). Rechia, Friedrichsen e Tschoke (2011), ao pesquisarem a Praça do Redentor, encontraram o lazer como único motivo para visitação da praça. Hildebrand (2001), por outro lado, encontrou que a maioria dos usuários utilizam os parques de Curitiba como ponto de encontro, representando $26,2 \%$ do total, seguidos por atividade física, com $20,7 \%$, e contato com a natureza, com $17,6 \%$.

Dos usuários entrevistados, a maioria usa a praça todos os dias, representando $56,9 \%$, e $27,2 \%$ usam a praça toda semana, sendo que apenas $15,9 \%$ dos entrevistados usam a praça em uma frequência menor. Silva et al. (2008) também encontraram uma frequência de uso das praças maior semanalmente, com $35,5 \%$, e diariamente, com $24,8 \%$. Por outro lado, os parques de Curitiba são visitados diariamente apenas por 14,4\% de seus usuários (HILDEBRAND, 2001). Tanto o motivo quanto a frequência de uso são diferentes entre as tipologias parque e praça. $A$ praça tem por característica primordial o seu papel social e devido à forma em que é inserida na malha urbana, funciona como um pequeno paraíso utilizado diariamente pela população no período de descanso. 
Dados referentes à percepção dos usuários das praças de Curitiba estão na figura 4 a seguir.

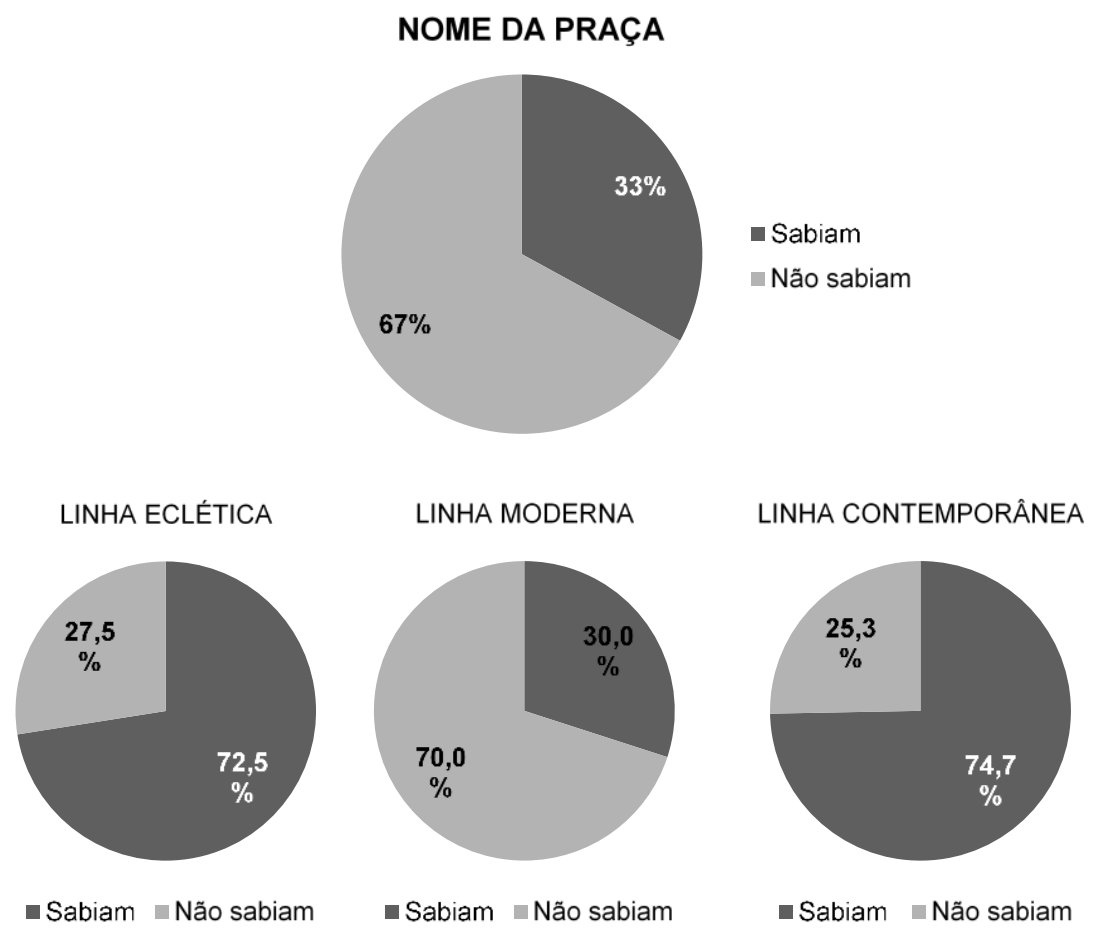

ÉPOCA DE CRIAÇÃO DA PRAÇA

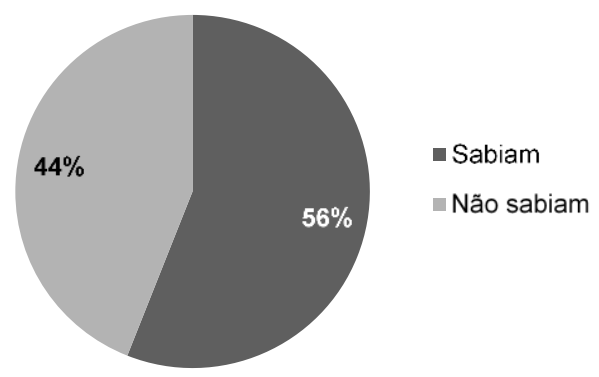

LINHA ECLÉTICA

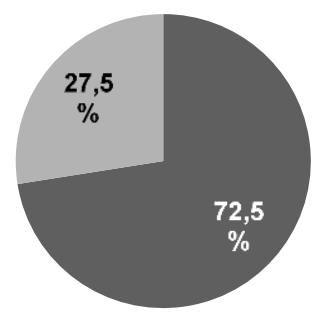

- Sabiam $=$ Não sabiam
LINHA MODERNA

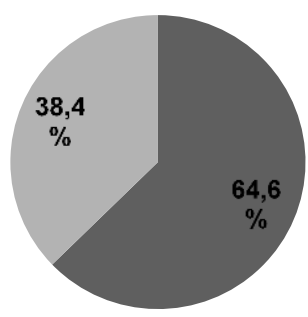

- Sabiam - Não sabiam
LINHA CONTEMPORÂNEA

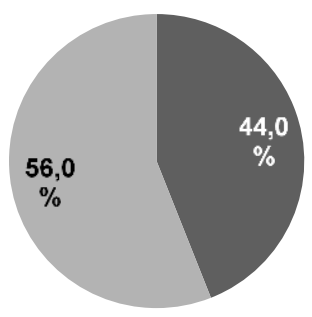

- Sabiam @ Não sabiam

Figura 4. Conhecimento dos usuários quanto ao nome e época de criação das praças de Curitiba-PR Figure 4. Users' knowledge about the name and time of creation of Curitiba-PR's squares 
No geral, 66,9\% não sabiam o nome da praça onde estava sendo realizada a entrevista, e $33,1 \%$ sabiam. Analisando por linha projetual paisagística, este resultado torna-se distinto. Nas praças ecléticas, apenas $27,5 \%$ das pessoas não sabiam o nome da praça, contra $72,5 \%$ que sabiam. Isso se dá pelas praças ecléticas serem mais antigas e mais centrais, e assim fazerem mais parte da identidade e do imaginário da população da cidade. Já nas praças modernas, 70\% dos usuários não sabiam o nome da praça, enquanto $30 \%$ sabiam. A mesma coisa para as praças contemporâneas, onde $74,67 \%$ não sabiam o nome e $25,33 \%$ sabiam.

Melo e Romanini (2008), ao pesquisarem sobre a Praça Ernesto Tochetto em Passo Fundo (RS), constataram que $42 \%$ dos usuários não sabiam o nome da praça. Segundo estes autores, este dado revela o desconhecimento da identidade sociocultural que estes espaços traduzem, principalmente entre os mais jovens, diferentemente do observado nesta pesquisa. Durante as entrevistas percebeu-se que não saber o nome não significava necessariamente desconhecimento ou que o entrevistado não se importava com a praça, mas sim que muitas praças possuem "apelidos", levando o nome do bairro, da igreja, de um colégio próximo, ou de seus elementos, como o caso da Praça Garibaldi, conhecida como Praça do Cavalo Babão, ou da Praça do Redentor, conhecida como Praça do Gaúcho.

Ao serem questionados sobre a data de criação das praças onde estavam, 56,0\% dos entrevistados tinham noção da época em que elas foram criadas, contra 44,0\% que erraram. Novamente, o maior número de acertos foi nas praças ecléticas, pelos mesmos motivos da pergunta anterior. Destas praças, 72,5\% acertaram a data de criação e 27,5\% erraram. Nas praças modernas, $64,62 \%$ acertaram e $35,38 \%$ erraram, e nas praças contemporâneas, $44 \%$ acertaram e $56 \%$ erraram.

Apesar da maioria dos usuários não saberem o nome das praças, a maioria soube dizer quando a praça foi criada. Isto se deve ao papel da praça no imaginário das pessoas, tanto como referencial histórico, como enquanto memória de infância.

Foi pedido aos usuários que escolhessem uma entre três palavras dadas para descrever a praça, sendo estas palavras-chave que evocavam características predominantes das linhas projetuais paisagísticas brasileiras. Estas palavras eram: "clássica" para a linha eclética, "nacionalista" para a linha moderna, e "inovadora" para a linha contemporânea. As respostas dadas pelos usuários foram comparadas com a linha projetual paisagística da praça em que estavam (FIGURA 5).

Apenas $27,2 \%$ acertaram a palavra relacionada com a linha paisagística da praça. Nas praças ecléticas, $72,5 \%$ acertaram; nas praças modernas 12,3\%; e nas praças contemporâneas $28,0 \%$. Este resultado se deu, pois a palavra-chave da linha projetual paisagística eclética ("clássica") foi a palavra mais usada, independente da linha da praça. Isso, possivelmente, porque a palavra "clássica" evocava aos entrevistados a imagem da praça da infância, da praça 
do bairro, e não de uma praça eclética, fato que pôde ser percebido por meio de conversas informais durante a realização das entrevistas.

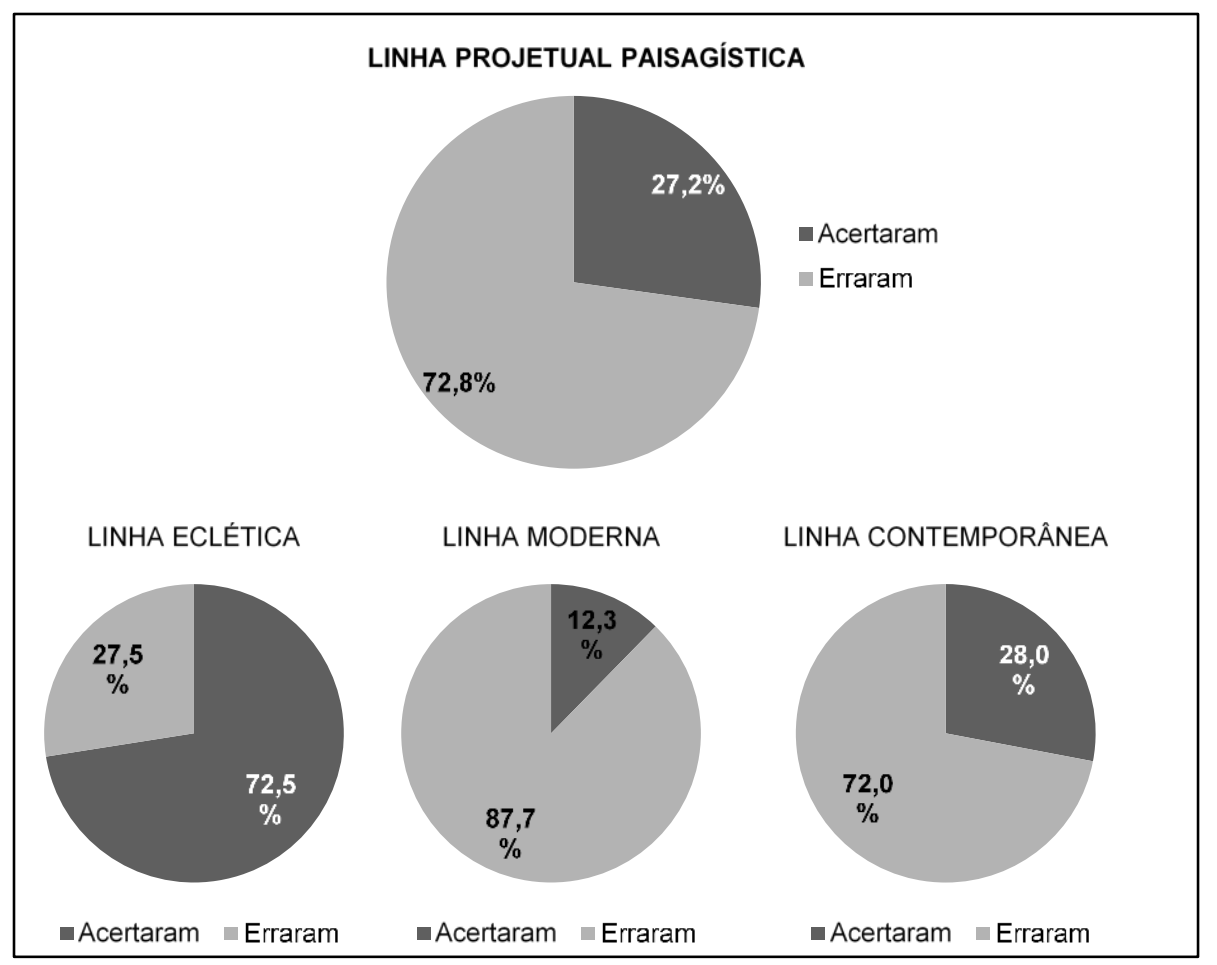

Figura 5. Conhecimento dos usuários quanto à linha projetual paisagística das praças de Curitiba-PR Figure 5. Users' knowledge about the landscape styles of Curitiba-PR's squares

Para se avaliar a percepção dos usuários sobre os elementos de composição paisagística das praças de Curitiba, foi perguntado qual elemento existente na praça chamava mais atenção ao usuário. Foram citados 22 grupos de elementos (FIGURA 6). As árvores foram os elementos de composição paisagística das praças públicas de Curitiba mais citados pelos entrevistados, $40 \%$ disse que é este o elemento que chama a maior atenção na área verde. Em segundo lugar ficou o parquinho com $14,7 \%$ e em terceiro o gramado com $12,2 \%$.

Nas praças ecléticas, as árvores foram citadas por $52,5 \%$ dos entrevistados, sendo que os chafarizes ficaram em segundo lugar, com $20 \%$, e as flores em terceiro, com $17,5 \%$. Nas praças modernas, $36,92 \%$ citaram as árvores, $15,38 \%$ o gramado e $12,31 \%$ as igrejas do entorno. Nas praças contemporâneas, 40\% citaram as árvores, 23,33\% citaram os parquinhos e $12 \%$ gramado. Portanto, pode-se notar que além das árvores, as espécies herbáceas também são notadas pela população, sendo como flores ou como gramado. 


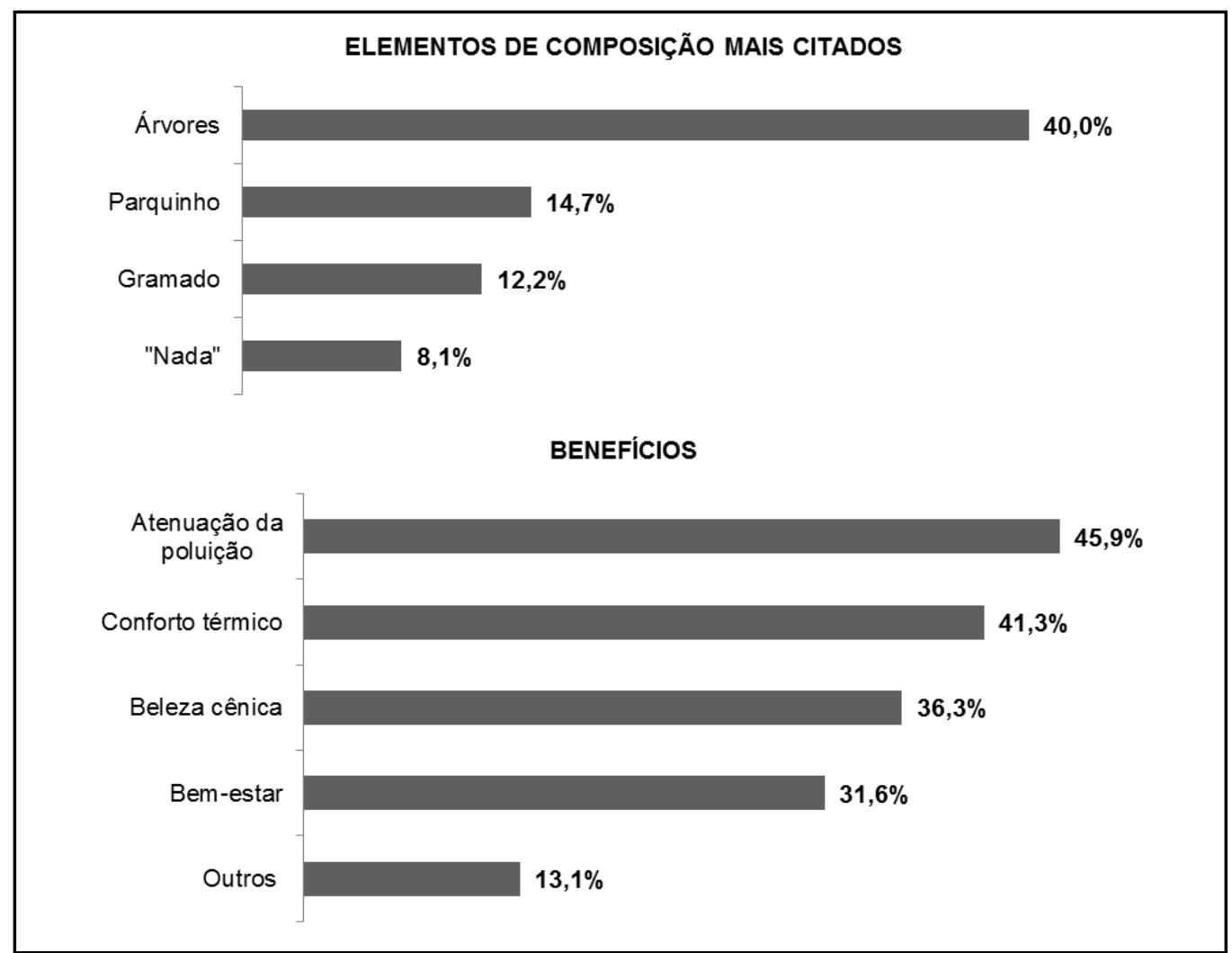

Figura 6. Elementos de composição e benefícios da vegetação mais citados pelos usuários das praças de Curitiba-PR

Figure 6. Most cited compositional elements and vegetation benefits by Curitiba-PR's squares users

Em suas pesquisas, Hildebrand (2001) e Silva et al. (2008) também encontraram dados que confirmam a importância da vegetação para os usuários das áreas verdes urbanas. Os usuários entrevistados por Hildebrand (2001) afirmaram que o contato com a natureza é a principal atração dos parques de Curitiba, enquanto Silva et al. (2008) constataram que as árvores e arbustos existentes na praça estudada agradam à maioria dos usuários, pois ambos receberam dos entrevistados um conceito "bom". Para Tuan (2013), as árvores são plantadas para obtenção de seus benefícios ambientais e estéticos, mas seu valor real pode ser relacionado às experiências íntimas por elas proporcionadas. Cada árvore é um lugar potencial para encontros afetuosos e espontâneos.

Os entrevistados foram questionados quanto aos benefícios que a vegetação existente na praça gera para a cidade de Curitiba e para a sua população. Os benefícios mais citados foram a atenuação da poluição, lembrada por $45,9 \%$ dos usuários, o conforto térmico, com $41,3 \%$, a beleza cênica, com $36,2 \%$, e o bem-estar, com $31,6 \%$.

Entre os demais benefícios, que representam $13,1 \%$ das respostas, foram citados a conservação da natureza, o abrigo para a fauna, a quebra da paisagem urbana, a infiltração da água, o contato com a natureza, a valorização imobiliária e a educação ambiental. 
Este resultado mostra que os usuários das praças públicas de Curitiba identificam a importância da vegetação que as compõem, além de conhecer diversos benefícios que esta vegetação proporciona.

Diversos estudos levantaram a percepção das populações urbanas sobre os benefícios gerados pela arborização urbana, interpretados na tabela 3 .

Tabela 3. Resultados de diferentes estudos de percepção sobre os benefícios da arborização urbana Table 3. Results from diverse studies about the perception of urban forest benefits

\begin{tabular}{|c|c|c|c|c|}
\hline Estudos & Cidade & № entrevistas & Principais benefícios & \\
\hline \multirow{3}{*}{ Este estudo } & \multirow{3}{*}{ Curitiba - PR } & \multirow{3}{*}{320} & Atenuação da poluição & $45,9 \%$ \\
\hline & & & Conforto térmico & $41,3 \%$ \\
\hline & & & Beleza cênica & $31,6 \%$ \\
\hline \multirow{3}{*}{$\begin{array}{l}\text { Ho et al } \\
2015\end{array}$} & \multirow{3}{*}{ Mandirituba - PR } & \multirow{3}{*}{62} & Atenuação da poluição & $61 \%$ \\
\hline & & & Diminuição da temperatura & $19 \%$ \\
\hline & & & Menor impacto da chuva & $16 \%$ \\
\hline \multirow{3}{*}{$\begin{array}{l}\text { Silva, E. C. R. et al } \\
2015\end{array}$} & \multirow{3}{*}{ Altamira - PA } & \multirow{3}{*}{43} & Sombra & $48 \%$ \\
\hline & & & Conforto térmico & $38 \%$ \\
\hline & & & Atenuação da poluição & $8 \%$ \\
\hline \multirow{3}{*}{$\begin{array}{l}\text { Costa et al } \\
2013\end{array}$} & \multirow{3}{*}{ Fortaleza-CE } & \multirow{3}{*}{274} & Diminuição da temperatura & $53,6 \%$ \\
\hline & & & Beleza cênica & $17,9 \%$ \\
\hline & & & Atenuação da poluição & $12 \%$ \\
\hline \multirow{3}{*}{$\begin{array}{c}\text { Monteiro et al } \\
2013\end{array}$} & \multirow{3}{*}{ Curitiba - PR } & \multirow{3}{*}{50} & Aspectos ecológicos & $68 \%$ \\
\hline & & & Aspectos sociais & $44 \%$ \\
\hline & & & Aspectos estéticos & $42 \%$ \\
\hline \multirow{3}{*}{$\begin{array}{l}\text { Souza et al } \\
2013\end{array}$} & \multirow{3}{*}{ Alegre-ES } & \multirow{3}{*}{113} & Sombra & $52 \%$ \\
\hline & & & Conforto térmico & $31 \%$ \\
\hline & & & Atenuação da poluição & $17 \%$ \\
\hline \multirow{3}{*}{$\begin{array}{l}\text { Gross et al } \\
2012\end{array}$} & \multirow{3}{*}{ Lages - SC } & \multirow{3}{*}{110} & Bem-estar & $91,8 \%$ \\
\hline & & & Sombra & $65,0 \%$ \\
\hline & & & Conforto térmico & $44,4 \%$ \\
\hline \multirow{3}{*}{$\begin{array}{l}\text { Araújo et al } \\
2010\end{array}$} & \multirow{3}{*}{$\begin{array}{c}\text { Campina Grande } \\
\text { - PB }\end{array}$} & \multirow{3}{*}{100} & Sombra & $60 \%$ \\
\hline & & & Conforto térmico & $24 \%$ \\
\hline & & & Atenuação da poluição & $10 \%$ \\
\hline \multirow{3}{*}{$\begin{array}{l}\text { Lacerda et al } \\
2010\end{array}$} & \multirow{3}{*}{$\begin{array}{l}\text { São José de } \\
\text { Piranhas - PB }\end{array}$} & \multirow{3}{*}{140} & Conforto térmico & $66 \%$ \\
\hline & & & Sombra & $32 \%$ \\
\hline & & & Beleza cênica & $2 \%$ \\
\hline \multirow{3}{*}{$\begin{array}{l}\text { Hildebrand } \\
2001\end{array}$} & \multirow{3}{*}{ Curitiba - PR } & \multirow{3}{*}{1.831} & Lazer & $27,5 \%$ \\
\hline & & & Bem-estar & $25,5 \%$ \\
\hline & & & Beleza cênica & $15,1 \%$ \\
\hline
\end{tabular}

Os principais benefícios citados por estudos de percepção da arborização urbana são: sombra, conforto térmico, diminuição da temperatura, atenuação da poluição, beleza cênica e bem-estar. A comparação entre estes estudos demonstra que, em diversas cidades brasileiras, a população reconhece o papel da arborização urbana, principalmente em relação à sua influência no microclima, e que os resultados encontrados nas praças de Curitiba não foram diferentes. 


\section{CONCLUSÃO}

Os usuários das praças de Curitiba-PR mostraram-se atraídos para as áreas verdes principalmente pela sua função social, sendo que a maioria usufrui do espaço diariamente para seu descanso e lazer.

As praças criadas durante a época da linha projetual paisagística eclética são as mais conhecidas pelos seus usuários, devido à sua localização central e ao seu tempo de existência. O elemento de composição paisagística mais citado pelos usuários foi a árvore, o que demonstra a importância da arborização destas áreas para a população.

A praça tende a ser a área verde mais presente na rotina diária dos habitantes da cidade, devido à sua ampla distribuição e seus elementos de composição paisagística voltados à sociabilidade. Sendo assim, conhecer o perfil dos usuários e sua percepção quanto aos elementos que compõem as praças permite conhecer a dinâmica de uso e a importância destas áreas verdes para a população urbana e reforçar a necessidade de manutenção e criação de praças nas cidades.

\section{REFERÊNCIAS}

ALRECK, P. L.; SETTLE, R. B. The survey research handbook. 3rd ed. New York: McGrawHill//rwin, 2004. 463p.

ARAÚJO, J. L. O.; DE ARAÚJO, A. C.; DE ARAÚJO, A. C. Percepção ambiental dos residentes do bairro Presidente Médici em Campina Grande-PB, no tocante à arborização local. Revista da Sociedade Brasileira de Arborização Urbana, Piracicaba, v.5, n.2, 2010.

BAHLS, A. V. D. S. Praças de Curitiba: espaços verdes na paisagem urbana. Curitiba: Fundação Cultural de Curitiba, 2006.

BIONDI, D.; LIMA NETO, E. M. Distribuição espacial e toponímia das praças de Curitiba - PR. Revista da Sociedade Brasileira de Arborização Urbana, Piracicaba, v. 7, n. 3, 2012.

BRÍGIDO, N. M.; HIRAU, H. A Praça Victor Civita e o desenvolvimento sustentável: uma avaliação do uso, apropriação e imaginário. TÓPOS, Presidente Prudente, v. 5, n. 2, p. 09-20, 2011.

CARNEIRO, A. R. S.; SILVA, A. D. F.; MAFRA, F. Restaurando o jardim moderno de Burle Marx: a Praça Faria Neves no Recife - PE. In: SEMINÁRIO DOCOMOMO, 7., 2007, Porto Alegre. Anais... Porto Alegre: DOCOMOMO, 2007. p. 1-14.

COSTA, C. G. F.; BEZERRA, R. F.; FREIRE, G. S. S. Avaliação da percepção da arborização urbana em Fortaleza. Revista da Sociedade Brasileira de Arborização Urbana, Piracicaba, v. 8, n. 4, 2013. 
GROSS, A.; DORS, P.; CAMPOS, K. A.; SILVA, A. C; HIGUCHI, P. Percepção dos moradores e avaliação da arborização em bairros periféricos na cidade de Lages, SC. Revista da Sociedade Brasileira de Arborização Urbana, Piracicaba, v. 7, n. 2, 2012.

HILDEBRAND, E. Avaliação econômica dos benefícios gerados pelos parques urbanos: estudo de caso em Curitiba - PR. 148 f. Tese (Doutorado em Engenharia Florestal). Universidade Federal do Paraná, 2001.

HO, T. L.; KOVALSYKI, B.; ZAMPRONI, K.; BIONDI, D. Percepção dos moradores sobre a arborização de ruas da região central de Mandirituba/PR. Revista da Sociedade Brasileira de Arborização Urbana, Piracicaba, v. 10, n. 3, 2015.

INSTITUTO BRASILEIRO DE GEOGRAFIA E ESTATÍSTICA (IBGE). Cidades: Curitiba. Disponível em: <http://goo.gl/bcT5lp>. Acesso em: 05/03/2016.

INSTITUTO DE PESQUISA E PLANEJAMENTO URBANO DE CURITIBA (IPUCC). Curitiba em dados. Disponível em: <http://goo.gl/4IZHZg>. Acesso em: 23/01/2016.

LACERDA; N. P.; SOUTO, P. C.; DIAS; R. S.; SOUTO, L. S.; SOUTO, J. S. Percepção dos residentes sobre a arborização da cidade de São José de Piranhas-PB. Revista da Sociedade Brasileira de Arborização Urbana, Piracicaba, v. 5, n. 4, 2010.

MELO, E. F. R. Q.; ROMANINI, A. Praça Ernesto Tochetto: importância da sua preservação histórica e aspectos de sua arborização. Revista da Sociedade Brasileira de Arborização Urbana, Piracicaba, v. 3, n. 1, p. 54-72, 2008.

MONTEIRO, M. M. G.; TETTO, A. F.; BIONDI, D.; SILVA, R. R. S. Percepção dos usuários em relação à arborização da Avenida Cândido de Abreu - Curitiba - PR. Revista da Sociedade Brasileira de Arborização Urbana, Piracicaba, v. 8, n. 2, 2013.

OLIVEIRA, M. D.; PERETTI, C.; BUDKE, J. C.; SANTOS, S. C. D.; CORAZZA, T.; GOMES, S.; QUADROS, F. R. D.; DECIAN, V. S.; ZANIN, M. E. Reflexos da evolução urbana sobre a arborização em Erechim, Sul do Brasil. Revista da Sociedade Brasileira de Arborização Urbana, Piracicaba, v. 8, n. 2, 2013.

RECHIA, S.; FRIEDRICHSEN, V. M.; TSCHOKE, A. Lazer e cidade: em foco a Praça do "Gaúcho" em Curitiba. Licere, Belo Horizonte, v. 14, n. 3, p. 1-19, 2011.

ROBBA, F.; MACEDO, S. S. Praças Brasileiras. Coleção Quapá, 3.ed. São Paulo, 2010.

SILVA, A. T. D.; TAVARES, T. S.; PAIVA, P. D. D. O.; NOGUEIRA, D. A. As praças Dr. Augusto Silva e Leonardo Venerando Pereira, 1701 Lavras - MG, segundo a visão de seus frequentadores. Ciência e Agrotecnologia, Lavras, v. 32, n. 6, 2008.

SILVA, E. C. R.; ALVEZ, F. B.; SILVA, I. I. S.; CARVALHO, B. C.; ALMEIDA, J. M.; MAGALHÃES, R. C. Percepção da população quanto à arborização na zona central histórica de Altamira-PA. Revista da Sociedade Brasileira de Arborização Urbana, Piracicaba, v. 10, n. 3, 2015.

SILVA, K. M. M; BARRETO, R. C.; CHAGAS, N. J. H., CARNEIRO, A. R. S. Inventário da vegetação cultivada na Praça da República: um estudo para a conservação e tombamento dos jardins de Burle Marx. Revista Brasileira de Biociências, Porto Alegre, v. 5, n.1, 2007.

SECRETARIA MUNICIPAL DE MEIO AMBIENTE DE CURITIBA (SMMA). Plano municipal de controle ambiental e desenvolvimento sustentável. Curitiba, 2008. 
SOUZA; S. M.; CARDOSO, A. L.; SILVA, A. G. Estudo da percepção da população sobre a arborização urbana, no município de Alegre-ES. Revista da Sociedade Brasileira de Arborização Urbana, Piracicaba, v. 8, n. 2, 2013.

TUAN, Y. Espaço e lugar: a perspectiva da experiência. Londrina: Eduel, 2013.

VOLPE-FILIK, A.; SILVA, L. F.; LIMA, A. M. P. Avaliação da arborização de ruas do bairro São Dimas na cidade de Piracicaba-SP através de parâmetros qualitativos. Revista da Sociedade Brasileira de Arborização Urbana, Piracicaba, v.2, n.1, 2007. 